\title{
REVIEW
}

\section{Prevention of exacerbations of COPD with pharmacotherapy}

\author{
M. Miravitlles
}

ABSTRACT: Exacerbations are a frequent event in the evolution of chronic obstructive pulmonary disease (COPD) patients. Individuals with COPD have a mean of 1-3 episodes per year, some of which lead to hospital admission and may even be a cause of death. The importance of COPD exacerbations has become increasingly apparent due to the impact these episodes have on the natural history of disease. It is now known that frequent exacerbations can adversely affect health-related quality of life and short- and long-term pulmonary function. Optimising treatment for stable COPD will help to reduce exacerbations.

Long-acting bronchodilators, alone or combined with inhaled corticosteroids, have demonstrated efficacy in reducing the rate of exacerbations in patients with COPD. Other innovative approaches are being investigated, such as the long-term use of macrolides or the use of antibiotics in an effort to suppress bronchial colonisation and consequent exacerbations. Other drugs, such as mucolytics and immunomodulators, have recently provided positive results.

Non-pharmacological interventions such as rehabilitation, self-management plans and the maintenance of high levels of physical activity in daily life are also useful strategies to prevent exacerbations in patients with COPD and should be implemented in regular clinical practice.

KEYWORDS: Antibiotics, bronchodilators, chronic obstructive pulmonary disease, exacerbations, infection, prevention

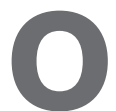
bstructive lung diseases, particularly chronic obstructive pulmonary disease (COPD) are one of the main causes of morbidity and mortality in developed countries. It is estimated that more than 15 million people in the USA have COPD and more than 12 million have chronic bronchitis [1], with these numbers having increased over recent decades. The ageadjusted mortality rate from COPD doubled from 1970 to 2002 in the USA, whereas mortality rates from stroke and heart disease decreased by $63 \%$ and $52 \%$, respectively [2].

The prevalence of COPD in Spain is $10.2 \%$ in adults between $40-80$ yrs of age, although only $27 \%$ are diagnosed [3]. This prevalence may even increase in the future. In fact, an international survey showed that up to $11.8 \%$ of subjects aged between 20-44 yrs had chronic bronchitis, characterised by chronic respiratory symptoms of cough and sputum production and $3.6 \%$ had Global Initiative for Chronic Obstructive Lung Diseases stages I to III COPD with impairment in lung function [4], which is remarkable considering the young age of the participants.
The chronic and progressive course of COPD is often aggravated by short periods of increasing symptoms, particularly increasing cough, dyspnoea and sputum production which can become purulent. Exacerbations have been demonstrated to have a negative impact on the quality of life of patients with COPD $[5,6]$. Furthermore, acute exacerbations are the most frequent cause of medical visits, hospital admissions and death among patients with chronic lung disease [7]. Therefore, strategies aimed at reducing the frequency of exacerbations are a cornerstone of the treatment of COPD.

\section{DEFINITION AND FREQUENCY OF EXACERBATIONS}

Exacerbations are a frequent event in the natural history of COPD. Patients included in clinical trials have a mean of 1-3 exacerbations per year [8]. In an international observational study there was a significant relationship between the severity of airflow obstruction and an increased number of exacerbations per year; however, this relationship was weak, indicating that many other factors influence the risk of having an exacerbation [9].
CORRESPONDENCE M. Miravitlles

Servei de Pneumologia

Hospital Clínic

Villarroel 170

08036 Barcelona

Spain

E-mail: marcm@separ.es

Received

March 162010

Accepted after revision:

March 232010

PROVENANCE

Publication of this peer-reviewed article was supported by Dompé SPA, Italy (unrestricted grant, European Respiratory Review issue 116) 
It is important to underline that many exacerbations remain unreported to the physician and are underestimated by the patient or are self-treated at home [5]. Consequently, the frequency of exacerbations depends on the definition used.

In an attempt to establish a uniform definition of exacerbations to be used as an outcome measure in clinical trials, the European Respiratory Society and the American Thoracic Society task force defined exacerbation as an increase in respiratory symptoms over baseline that usually requires a change in therapy [10].

It is evident that studies that define exacerbations with the use of diary cards tend to identify a greater number of episodes per year [5]; these are the non-reported exacerbations. Different studies have estimated that up to two thirds of exacerbations remain unreported to the physician and, therefore, no appropriate treatment is prescribed [5, 11]. One group has recently examined 132 patients during almost 3 yrs of followup carefully documenting exacerbations through the use of diary cards [12]. They also confirmed that patients with severe COPD (forced expiratory volume in $1 \mathrm{~s}$ (FEV1) $<30 \%$ predicted) experienced a higher exacerbation frequency (3.43 exacerbations per year) than those with moderate COPD (FEV1 $\geqslant 30 \%$ but $<80 \%$ pred) ( 2.68 exacerbations per year). Interestingly, the annual exacerbation frequency remained constant throughout the study period, although physiological and clinical recovery from exacerbations was significantly longer each year [12]. This suggests that frequent exacerbators have particular characteristics that make them prone to develop recurrent episodes. Nonetheless, the exact nature of these characteristics or risk factors has not yet been elucidated.

Repeated exacerbations may have an impact on the natural history of the disease. Patients with severe COPD and frequent exacerbations present an excessive decline in lung function over time [13]. Patients are frightened of exacerbations and have important limitations in their daily life activities because of these episodes $[14,15]$. The impact of exacerbations in the health status of patients with COPD was first observed by SEEMUNGAL et al. [5] in a cohort of severe patients over $1 \mathrm{yr}$ of follow-up. This observation was confirmed in patients with different degrees of severity, both in specialised hospital-based cohorts $[6,16]$ and in mild-to moderate patients in primary care [17].

Based on this evidence and on the expectations of the patients, for whom the prevention of exacerbations is an important unmet need of COPD treatment [14], the prevention of episodes should be one of the main goals of COPD treatment. Table 1 summarises most of the pharmacological interventions available for the prevention of exacerbations.

\section{PHARMACOLOGICAL PREVENTION OF EXACERBATIONS \\ Antimicrobials}

In clinical trials with antibiotics in exacerbations of COPD, a prolonged time to the next exacerbation has been observed in patients who eradicate the bronchial pathogen after an exacerbation [18, 19]. This suggests that in patients who effectively eradicate bacteria more time is needed to achieve the threshold of bacterial counts required for an exacerbation to occur, compared with patients who cure the exacerbation but in whom bacteria still persist after antibiotic treatment [20, 21]. This hypothesis would also explain why patients with acute exacerbations may be clinically cured even without eradication of the bacterial pathogen [22]. This is not proof that this particular bacterium is not the cause of the exacerbation, but rather demonstrates that the antibiotic only needs to reduce bacterial counts to below the threshold to eliminate symptoms. Nevertheless, if eradication also occurs, the time for a bacterial load above the threshold to be reached will be longer.

This quantitative or "fall and rise" hypothesis may explain the mechanism of bacterial exacerbations in patients with chronic bronchial colonisation and frequent exacerbations [21]. As demonstrated by SETHI et al. [23], in this group of patients the change in the serotype of the colonising bacteria may, in some cases, act as a trigger that initiates proliferation of microorganisms. Fall and rise may also explain the relapses that occur when bacteria have not been eradicated after antibiotic treatment of the exacerbation. In contrast, the change in the serotype of the infective bacteria may be crucial in patients who do not have frequent exacerbations, i.e. less than three in 1 yr. In a recent study SETHI et al. [24] demonstrated that no increase in bacterial counts was associated with the occurrence of exacerbations. Only Haemophilus influenzae presented significantly higher concentrations in sputum during exacerbations compared with stable COPD, but the magnitude of the difference was small. These results are against the hypothesis that merely an increase in bacterial counts is enough to initiate an exacerbation. New evidence is required on the complex relationship between microorganisms and the host.

Trials of antibiotic treatment of stable chronic bronchitis were conducted in the 1950s and 1960s with inconclusive results [25] and, as a result, the prescription of prophylactic antibiotics for COPD has not been recommended due to the controversial efficacy, risk of side-effects and the potential development of

\section{TABLE 1 Strategies aimed at preventing exacerbations}

Proven efficacy
Smoking cessation
LABAs: salmeterol, formoterol
Tiotropium
Combination therapy: LABA/ICS
Anti-influenza vaccine
Antipneumococcal vaccine ${ }^{\#}$
Rehabilitation
Physical exercise
Self-management plans
LVRS in selected patients
Questioned efficacy
Theophyllines
Prophylactic antibiotic in selected patients
Immunomodulators
Mucolytic agents
Antioxidants

LABA: long-acting $\beta_{2}$-agonist; ICS: inhaled corticosteroid; LVRS: lung volume reduction surgery. ${ }^{\#}$ : efficacy demonstrated in prevention of pneumonia but not in the prevention of exacerbations. 
bacterial resistance. However, the chronic use of macrolides in COPD has received increasing attention in recent years. The main objective to the existing studies was to prevent exacerbations, either bacterial or viral, via mechanisms other than antibacterial activity [26-28]. In fact, two of these studies, of 3 months [27] and 1 yr duration [28], respectively, did not observe any changes in bronchial bacterial flora. However, the latter study using erythromycin $250 \mathrm{mg}$ twice daily for $1 \mathrm{yr}$ observed a significant reduction of $35 \%$ in the frequency of exacerbations compared with placebo [28]. Instead, the rationale for the use of the fluoroquinolone moxifloxacin for the treatment of stable COPD is based on its antibacterial efficacy. Bacterial eradication reduces the inflammatory burden of the airways [29] and may eventually prevent the development of exacerbations [18, 20, 30]. Treatment with moxifloxacin has been efficacious in eradicating bacteria from the airways but new strains of colonising bacteria were present again after 8 weeks of antibiotic treatment, indicating that recolonisation is extremely frequent in a subset of patients with COPD [31]. These results suggest that efficacious eradicating treatment should be either maintained indefinitely or at least repeated in courses $\leqslant 8$ weeks. This strategy was used in a large 1-yr placebo-controlled trial with moxifloxacin administered in pulses every 8 weeks in patients with moderate-tosevere COPD and showed a significant reduction in the frequency of exacerbations, particularly in patients with purulent or muco-purulent sputum at the beginning of the study [32]. More evidence is required before clear recommendations can be established regarding the type of patients in whom the potential benefits of this treatment may outweigh the risks.

\section{Bronchodilators}

Initially, the impact of short-acting bronchodilators on the frequency of exacerbations was not considered in clinical trials. However, there are some data indicating that the addition of regular ipratropium therapy in COPD reduces the frequency of exacerbations [33]. The regular use of short-acting bronchodilators has been replaced by the more effective long-acting bronchodilators salmeterol and formoterol.

Most clinical trials investigating the efficacy of the long-acting bronchodilators in COPD were not designed to evaluate the rate of exacerbations as the primary variable. This may explain why there is a certain controversy regarding whether their use in monotherapy reduces the frequency and/or severity of the exacerbations. Initial data on salmeterol and formoterol in studies of $<3$ months suggest that exacerbations are not modified with the use of these drugs [34]. Nonetheless, it has been observed that the time until the first exacerbation is longer [35]. Formoterol has also been found to be effective in reducing the number of "bad days" (equivalent to mild exacerbations) in some studies [36], although in other reports it was not found to reduce moderate-severe exacerbations in more severe patients [37, 38]. These data led to certain doubts about possible differences between long-acting bronchodilators. However, a recent systematic review confirmed that these drugs reduce the risk of exacerbation by $23 \%$ (HR $0.77,95 \%$ CI $0.71-0.84)$, with the results being similar for both salmeterol and formoterol [39].
The Towards a Revolution in COPD Health (TORCH) trial demonstrated a significant $(15 \%, \mathrm{p}<0.001)$ reduction in moderate-tosevere exacerbations with salmeterol compared to placebo in a large population of COPD patients followed for 3 yrs [40], confirming the results observed in previous 1-yr trials with either salmeterol or formoterol [41].

Tiotropium bromide is a long-acting bronchodilator that has demonstrated clinical efficacy in significantly improving the FEV1, reducing the frequency of exacerbations and improving the health-related quality of life for patients with any stage of COPD $[42,43]$. The prolonged and persistent bronchodilation achieved with tiotropium may reduce the exacerbation and COPD-related hospitalisation rates. The effect of tiotropium treatment on the incidence of exacerbations has been determined (as a secondary outcome) in early registration studies.

More recent trials have been specifically designed to demonstrate the effect of tiotropium on the reduction in the frequency of exacerbations. The second characteristic of these studies is that patients in the placebo arm were allowed to receive other active drugs for COPD, such as long-acting $\beta_{2}$-adrenergics and/or inhaled corticosteroids (ICS). The first study was undertaken in 1,829 patients taking tiotropium for 6 months and demonstrated an additional benefit in the reduction of exacerbations $(p=0.037)$, hospitalisations $(p=0.047)$, unscheduled medical visits $(p=0.019)$ and days of antibiotic treatment $(p=0.015)$ [44]. The second study included 1,010 patients with a mean FEV1 of $48 \%$ pred who were followed for $1 \mathrm{yr}$. The frequency of exacerbations was reduced with tiotropium from 2.41 per year in the placebo group to 1.57 in the tiotropium group $(\mathrm{p}<0.001)$ [45]. It is of note that in the placebo group up to $61.6 \%$ of patients were already receiving ICS and $32.5 \%$ were being treated with long-acting $\beta_{2}$-agonists.

A recent Cochrane review summarises the results of the trials investigating the reduction of exacerbations with tiotropium [46]. In the same meta-analysis of studies that included data on exacerbations of COPD, the authors calculated that in order to reduce the total incidence of exacerbations by one episode the number of patients needed to treat (NNT) for $1 \mathrm{yr}$ was 13 individuals (95\% CI 10-21). The NNT to reduce hospitalisations for exacerbation by one episode was 38 (95\% CI 26-76). The Understanding Potential Long-Term Impacts on Function with Tiotropium (UPLIFT) trial included 5,993 patients who were followed for 4 yrs and, compared with controls, tiotropium significantly delayed time-to-first exacerbation (16.7 versus 12.5 months) and time-to-first hospitalisation for exacerbations (lower risk of hospitalisation: HR 0.86, $(95 \% \mathrm{CI}$ $0.78-0.95) ; p=0.002)$ [47]. Tiotropium also reduced the mean number of exacerbations by $14 \%$ (rate per patient-yr 0.73 versus 0.85 ; HR $0.86,95 \%$ CI $0.81-0.91 ; \mathrm{p}<0.001)$. It is important to highlight that the control group in the UPLIFT trial consisted of patients with usual treatment for COPD, which included ICS and/or long-acting $\beta_{2}$-agonists in up to $62 \%$ of cases at baseline and up to $73 \%$ of cases at any time during follow-up. The fact that the UPLIFT placebo group included patients treated with a long-acting bronchodilator and ICS may explain why there was a relatively low rate of exacerbation in this group compared with the placebo group of previous tiotropium studies [42, 43]. 
The mechanisms by which tiotropium or long-acting bronchodilators reduce exacerbations are not completely understood. A 1-yr, double-blind, randomised placebo-controlled trial in 142 patients with severe COPD demonstrated a reduction of $52 \%$ in the frequency of exacerbations in the tiotropium group $(p=0.001)$. Interestingly, there was no reduction in sputum or systemic markers of inflammation between the two treatment arms. In fact, interleukin- 8 levels were increased in the tiotropium arm, although the significance of this finding is still unknown [48]. Evidence suggests that the reduction in exacerbations may be mediated by stabilisation of the airways due to the prolonged bronchodilatation obtained by tiotropium and the reduction of air-trapping. This is further supported by evidence that lung volume reduction surgery reduces the frequency of exacerbations in patients in whom lung function improves after the intervention, basically by the same mechanical principle [49] and may also explain the reduction observed with long-acting bronchodilators.

\section{ICS}

The great efficacy of ICS in asthma has also led to their use in patients with COPD. Their use has been justified by the demonstration of the importance of inflammation in the aetiopathogenesis of the disease and by the fact that, to date, there is no specific anti-inflammatory for COPD apart from theophylline. Nonetheless, the characteristics of bronchial inflammation in COPD differ from those found in asthma, which may justify the lesser effect of the ICS in this setting [50].

The use of ICS in COPD has not been found to have any impact on disease progression in any of the clinical trials performed with this objective in different populations of COPD patients with different levels of FEV1 involvement and different smoking habits $[8,51]$. The effect of the ICS in reducing the number and severity of exacerbations is more consistent [52], especially in patients with a more altered pulmonary function with an FEV1 $<50 \%$ pred [53].

More recently, the TORCH trial demonstrated a reduction of $18 \%$ in the rate of moderate-to-severe exacerbations $(\mathrm{p}<0.001)$ in patients treated with fluticasone $500 \mu \mathrm{g}$ twice daily compared with placebo [40]. Interestingly, this reduction was even higher when the exacerbations requiring systemic corticosteroids were considered, in which the reduction was of $35 \%(p<0.001)$. In patients with stage II COPD, fluticasone reduced the frequency of exacerbations from 0.82 per patient per year to 0.68 (statistical significance not provided) [54].

The different treatment guidelines for COPD recommend the chronic use of ICS in patients with FEV $1<50 \%$ and frequent exacerbations (more than two per year) $[1,55]$ because of their impact on exacerbations and the ability of ICS to halt the deterioration in the state of health of these patients $[8,53]$. However, it remains to be demonstrated whether high doses of ICS are more clinically effective in COPD than lower doses. Neither can it be forgotten that the indefinite administration of high doses of ICS in patients with COPD, most of whom are elderly and with comorbidities, is not without the risk of either local [56] or systemic [57] adverse effects. Specifically, the presentation of pneumonia and osteoporosis as a complication of chronic treatment with ICS seems to be related to the dose administered [58,59]. Thus, it is reasonable to prescribe the minimum dosage that is clinically effective in patients receiving chronic treatment with ICS, although there is also little evidence indicating how, when and in what way the response can be evaluated.

\section{ICS and long-acting $\boldsymbol{\beta}_{2}$-agonists}

The addition of a long-acting bronchodilator (salmeterol or formoterol) and an ICS (fluticasone or budesonide) in the same inhaler represents advancement in the treatment of asthma and their efficacy has also recently been studied in COPD.

In a group of patients with moderate-severe COPD (FEV1 $<50 \%$ pred) including an unknown proportion of individuals with bronchial reversibility, combined treatment with budesonide/formoterol (BFC) achieved an increase in FEV1 of $15 \%$ compared with placebo [38]. It is important to note that patients treated with BFC presented a mean time to the first exacerbation of 254 days compared with the 96 days of the placebo group $(p=0.006)$. The patients treated with either of the two drugs separately achieved intermediate results [37]. Likewise, BFC achieved an improvement in lung function and a reduction of $25 \%$ in the number of exacerbations during $1 \mathrm{yr}$ of follow-up [41].

In the TORCH study, a total of 6,112 patients were randomised to receive fluticasone/salmeterol combination (FSC), placebo or one of the two components separately over the course of 3 yrs [40]. The main objective of the study was to determine the effect of the FSC combination on mortality by any cause over the 3-yr study period. The results demonstrated a reduction in mortality of $2.6 \%$ with FSC in absolute terms compared to placebo, representing a relative reduction of $17.5 \%$ which was almost statistically significant $(\mathrm{p}=0.052)$. The TORCH study confirmed the results of previous studies with respect to the reduction in exacerbations and the improvement in the quality of life with combination therapy. Regarding exacerbation, FSC reduced the frequency of moderate or severe exacerbations significantly (by 25\%) as well as hospitalisations (17\%) [40] Interestingly, this $25 \%$ reduction was the same as the reduction observed in the previous 1-yr trials with FSC [41]. In patients with stage II COPD, FSC reduced the frequency of exacerbations by $31 \%$ (95\% CI 19-40) from 0.82 per patient per year to 0.57 [54].

However, the small reduction in mortality observed in the TORCH study may, at least in part, be explained by the selection of the patients. One of the inclusion criteria was to have a negative bronchodilator test thereby reflecting a mean reversibility of the participants of only 3.7\% [40]. Therefore, TORCH explains the long-term effect of the combination of FSC in patients who are less susceptible to respond to ICS. On the contrary, a more recent study has compared FSC with salmeterol in the treatment of patients with severe COPD (FEV1 <50\%) [60], demonstrating a significant reduction during $1 \mathrm{yr}$ of $35 \%$ in the rate of moderate-to-severe exacerbations with FSC compared to treatment with salmeterol alone. This study did not take the reversibility of FEV1 into account among the inclusion criteria and indeed, the mean reversibility of the patients was of $7 \%$, being almost double that reported in TORCH. The result was a significant reduction in the frequency of exacerbations on adding fluticasone to the treatment with salmeterol. Similarly, in a recent study it was 
demonstrated that treatment with FSC at a dose of $250 \mu \mathrm{g} /$ $50 \mu \mathrm{g}$ every $12 \mathrm{~h}$ produced an increase in the area under the curve of $6 \mathrm{~h}$ in the FEV1, being more than double in reversible patients $\left(1.98 \mathrm{~L} \cdot \mathrm{h}^{-1}\right.$ in week 8$)$ than in irreversible patients $\left(0.4 \mathrm{~L} \cdot \mathrm{h}^{-1}\right)$, thereby providing more evidence of the different response to ICS or to combined treatment according to the response to the bronchodilation test [61]. Irrespective of these differences, the US studies with FSC at a dose of $250 \mu \mathrm{g} / 50 \mu \mathrm{g}$ b.i.d. demonstrated a significant reduction of exacerbations of $30.5 \%$, from 1.53 per patient per year with FSC to 1.06 with salmeterol alone, and a reduction to the risk of time to the first exacerbation by $25 \%(p=0.003)$ [62], results that were almost identical to those observed with the dose of $500 \mu \mathrm{g} / 50 \mu \mathrm{g}$ b.i.d.

The Investigating New Standards for Prophylaxis in Reducing Exacerbations (INSPIRE) study compared long-term treatment with tiotropium or FSC in a total of 1,323 patients with moderate-to-severe COPD (mean FEV1 of $40 \%$ pred) in a $2-y r$, double-blind, parallel group study. The results demonstrated no differences in the exacerbation rates of either treatment group with an annual exacerbation rate of 1.32 in the tiotropium group compared with 1.28 in the FSC group $(p=0.65)$ [63]. Another interesting result of the INSPIRE study was the demonstration of different types of exacerbations. Patients in the tiotropium arm experienced a significant reduction in exacerbations treated by the investigator with a course of antibiotics, whereas those in the FSC arm presented with a reduced number of exacerbations requiring treatment with a course of oral corticosteroids [63]. This finding suggests that in severe or very severe patients there might be an additive effect with the combination of different therapies in further reducing the frequency of exacerbations by different mechanisms of action [64].

This hypothesis has been tested in two clinical trials that attempted to analyse whether patients already receiving tiotropium as long-term maintenance therapy would benefit from the addition of a combination therapy of FSC or BFC. The optimal therapy of COPD to prevent exacerbations and improve quality of life (OPTIMAL study) was a randomised, double-blind, placebo-controlled trial designed to address this issue in a group of patients with moderate-to-severe COPD (mean FEV1 $\sim 40 \%$ pred). The proportion of patients in the tiotropium group who presented with an exacerbation $(62.8 \%)$ did not differ from that in the tiotropium plus FSC group $(60 \%)$ [65]. The number of hospitalisations in the group treated with tiotropium plus FSC was only reduced in patients with more severe disease suggesting that the more severe or at risk patients benefit from an intensification of therapy. A more recent study has compared the effect of the addition of BFC to treatment with tiotropium in patients with severe COPD (FEV1 pre-bronchodilator $<50 \%$ pred). Interestingly, the mean reversibility of these patients was $15 \%$ in absolute values or $5.6 \%$ in FEV1 (\% pred). The main outcome was an increase in FEV1 and the triple combination produced a significant increase in FEV1 at all the time-points over monotherapy with tiotropium. Nonetheless, despite the short trial duration of only 12 weeks, there was an important and significant reduction in exacerbations of $62 \%$ [66]. Based on the results of both studies, it can be concluded that patients with more severe disease may benefit in terms of improving lung function and reducing the risk of admissions with the addition of combined therapy to the pre-existing baseline treatment with tiotropium.

\section{Mucolytics}

In the long-term treatment of stable COPD other drugs such as mucolytics ( $N$-acetylcysteine (NAC), carbocysteine, ambroxol and others) have also been used with the primary objective of preventing exacerbations. These products have been frequently used [9], but the scientific evidence supporting their use has traditionally been insufficient.

Some studies have demonstrated that treatment with mucolytics is associated with a significant reduction in some parameters, such as the frequency of exacerbations, the number of days with symptoms of exacerbation and the number treatment courses of antibiotics compared with placebo [67]. However, many of these studies have important limitations such as a small sample size. Thus, most guidelines indicate that the evidence to recommend their generalised use of these drugs in the treatment of COPD remains insufficient $[1,55]$.

Among the so-called mucolytics, perhaps the drug most frequently used is NAC. Despite its known effects on mucus, more importance has recently been given to the therapeutic value derived from its antioxidant action. The BRONCUS study [68] did not demonstrate a significant overall reduction in the frequency of exacerbations in patients treated with NAC compared with placebo, although NAC reduced exacerbations only in the subgroup not receiving concomitant treatment with ICS. No significant differences were found in the reduction in lung function measured by FEV1 among the patients treated with NAC or with placebo [68]. The PEACE study [69] has demonstrated a significant reduction of $25 \%$ in the frequency of exacerbations with carbocysteine $1,500 \mathrm{mg} \cdot \mathrm{day}^{-1}$ versus placebo. Although the authors did not observe any interaction between carbocysteine and ICS or theophyllines, most of the patients did not receive treatment with long-acting bronchodilator or ICS [69].

\section{Immunomodulators}

Immunomodulators have been commercialised for years, being prepared from lyophilised bacterial extracts for oral administration with the aim of improving symptoms and preventing exacerbations. In a recent systematic review the results of 13 randomised, controlled clinical trials with placebo were analysed [70]. The authors of the review recognised that most of the studies are of low methodological quality and do not conclusively demonstrate an effect on the prevention of exacerbations [70]. The only significant effect found was a reduction in the intensity of the symptoms and a mean reduction in the duration of the exacerbations of 3 days, although the poor quality of the studies makes it necessary to interpret these results with caution [70].

AM3 (Inmunoferon $®$; Laboratories Cantabria, Madrid, Spain) is an immunomodulator able to partially re-establish the cytotoxic capacity of the natural killer cells and increase the phagocytic capacity of the circulating macrophages and neutrophils, both of which are affected in COPD [71]. In a recent randomised, double-blind study, 253 patients with COPD (mean FEV1 of $49 \%$ ) received AM3 or placebo during a 6-month period. The patients treated with AM3 showed a 
TABLE 2 Reduction in exacerbations with pharmacotherapy in selected clinical trials

\begin{tabular}{|c|c|c|c|c|}
\hline First author [Ref.] & Drug & Dose & Trial duration & Reduction in exacerbations \% \\
\hline SeEmungal [28] & Erythromycin & $250 \mathrm{mg}$ every $12 \mathrm{~h}$ & $1 \mathrm{yr}$ & 35 \\
\hline Calverley $[40]$ & Fluticasone & $500 \mu \mathrm{g}$ every $12 \mathrm{~h}$ & 3 yrs & 18 \\
\hline KARDOS [60] & Fluticasone & $500 \mu \mathrm{g}$ every $12 \mathrm{~h}$ & $1 \mathrm{yr}$ & $35^{\circ}$ \\
\hline SZAFRANSKI [38] & Budesonide & $320 \mu \mathrm{g}$ every $12 \mathrm{~h}$ & $1 \mathrm{yr}$ & 15 \\
\hline DUSSER [45] & Tiotropium & $18 \mu \mathrm{g} \cdot \mathrm{day}^{-1}$ & $1 \mathrm{yr}$ & 27 \\
\hline BARR [46] & Tiotropium & $18 \mu \mathrm{g} \cdot \mathrm{day}^{-1}$ & $4 \mathrm{yrs}$ & $14^{+}$ \\
\hline HubBaRd [59] & $\mathrm{BFC}$ & $320 \mu \mathrm{g}$ every $12 \mathrm{~h}$ & $1 \mathrm{yr}$ & 25 \\
\hline Calverley $[40]$ & FSC & $500 / 50 \mu g$ every $12 \mathrm{~h}$ & 3 yrs & 25 \\
\hline FERGUSON [63] & FSC & $250 / 50 \mu g$ every $12 \mathrm{~h}$ & $1 \mathrm{yr}$ & 30.5 \\
\hline ZHENG [69] & Carbocysteine & $1500 \mathrm{mg} \cdot \mathrm{day}^{-1}$ & $1 \mathrm{yr}$ & $25 \%$ \\
\hline
\end{tabular}

significant improvement in their health status at the end of the study compared with placebo evaluated using the St George's questionnaire; although the reduction in the number of exacerbations observed was not significant [72]. The effect of the treatment was greater in the patients who also received ICS during the study [73]. Further studies of longer duration are necessary to determine the possible effect on the prevention of exacerbations.

Other treatments may have an effect in reducing exacerbations. The use of anti-influenza [74] and anti-pneumococcal vaccinations [75] are useful in reducing the frequency of lower respiratory tract infections and pneumonia in COPD. A summary of the therapies that have demonstrated an effect in reducing exacerbations is presented in table 2.

Exacerbations significantly impair both the short- and longterm quality of life of COPD patients and cause a reduction in physical activity. Furthermore, the reduction in physical activity is a risk factor for hospitalisations and death in COPD [77]. Self-management plans and rehabilitation programmes, in addition to pharmacotherapy, are effective in reducing the exacerbations and the impact of these episodes on the natural history of the disease $[78,79]$.

Considering all these strategies together, the management of patients with COPD has improved significantly during the last decades. The frequency of exacerbations has been reduced in general with the use of the new drugs and a more comprehensive approach to the patients that includes smoking cessation, exercise, rehabilitation and improved nutrition. However, more research is required to understand the differential characteristics of the patients and, accordingly, to prescribe the best individualised treatment for each and every patient with COPD.

\section{STATEMENT OF INTEREST}

M. Miravitlles has received an honorarium for participating in an advisory board for Dompé SPA.

\section{REFERENCES}

1 Celli BR, MacNee W, Agusti E, et al. Standards for the diagnosis and treatment of patients with COPD: a summary of the ATS/ERS position paper. Eur Respir J 2004; 23: 932-946.

2 Jemal A, Ward E, Hao Y, et al. Trends in the leading causes of death in the United States, 1970-2002. JAMA 2005; 294: 1255-1259.

3 Miravitlles M, Soriano JB, García-Río F, et al. Prevalence of COPD in Spain: impact of undiagnosed COPD on quality of life and daily life activities. Thorax 2009; 64: 863-868.

4 De Marco R, Accordini S, Cerveri I, et al. An international survey of chronic obstructive pulmonary disease in young adults according to GOLD stages. Thorax 2004; 59: 120-125.

5 Seemungal TAR, Donaldson GC, Paul EA, et al. Effect of exacerbation on quality of life in patients with chronic obstructive pulmonary disease. Am J Respir Crit Care Med 1998; 157: 1418-1422.

6 Miravitlles M, Ferrer M, Pont A, et al. Effect of exacerbation on quality of life in patients with chronic obstructive pulmonary disease. A 2 year follow-up study. Thorax 2004; 59: 387-395.

7 Burrows B, Bloom JW, Traver GA, et al. The course and prognosis of different forms of chronic airways obstruction in a sample from the general population. N Engl J Med 1987; 317: 1309-1314.

8 Burge PS, Calverley PMA, Jones PW, et al. Randomised, double blind, placebo controlled study of fluticasone propionate in patients with moderate to severe chronic obstructive pulmonary disease: the ISOLDE trial. BMJ 2000; 320: 1297-1303.

9 Miravitlles M, Murio C, Tirado-Conde G, et al. Geographic differences in clinical characteristics and management of COPD: the EPOCA study. Int J Chron Obstruc Pulmon Dis 2008; 3: 803-814.

10 Cazzola M, MacNee W, Martinez FJ, et al. Outcomes for COPD pharmacological trials: from lung function to biomarkers. Eur Respir J 2008; 31: 416-468.

11 Langsetmo L, Platt RW, Ernst $\mathrm{P}$, et al. Underreporting exacerbation of chronic obstructive pulmonary disease in a longitudinal cohort. Am J Respir Crit Care Med 2008; 177: 396-401. 
12 Donaldson G, Seemungal T, Patel I, et al. Longitudinal changes in the nature, severity and frequency of COPD exacerbations. Eur Respir J 2003; 22: 931-936.

13 Donaldson GC, Seemungal TAR, Bhomik A, et al. Relationship between exacerbation frequency and lung function decline in chronic obstructive pulmonary disease. Thorax 2002; 57: 847-852.

14 Miravitlles M, Anzueto A, Legnani D, et al. Patient's perception of exacerbations of COPD: the PERCEIVE study. Respir Med 2007; 101: 453-460.

15 Kessler R, Stahl E, Vogelmeier C, et al. Patient understanding, detection, and experience of COPD exacerbations. An observational, interview-based study. Chest 2006; 130: 133-142.

16 Miravitlles M, Calle M, Alvarez-Gutierrez F, et al. Exacerbations, hospital admissions and impaired health status in chronic obstructive pulmonary disease. Qual Life Res 2006; 15: 471-480.

17 Llor C, Molina J, Naberan K, et al. Exacerbations worsen the quality of life of chronic obstructive pulmonary disease patients in primary healthcare. Int J Clin Pract 2008; 62: 585-592.

18 Chodosh S, Schreurs A, Siami G, et al. The efficacy of oral ciprofloxacin $v s$ clarithromycin for the treatment of acute bacterial exacerbations of chronic bronchitis. Clin Infect Dis 1998; 27: 730-738.

19 Wilson R, Allegra L, Huchon G, et al. Short and long-term outcomes of moxifloxacin compared to standard antibiotic treatment in acute exacerbations of chronic bronchitis. Chest 2004; 125 : 953-964.

20 Chodosh S. Clinical significance of the infection-free interval in the management of acute bacterial exacerbations of chronic bronchitis. Chest 2005; 127: 2231-226.

21 Miravitlles M. Exacerbations of chronic obstructive pulmonary disease: when are bacteria important? Eur Respir J 2002; 20: Suppl. 36, 9s-19s.

22 Wilson R, Kubin R, Ballin I, et al. Five day moxifloxacin therapy compared with 7 day clarithromycin therapy for the treatment of acute exacerbations of chronic bronchitis. J Antimicrob Chemother 1999; 44: 501-513.

23 Sethi S, Evans N, Grant BJ, et al. New strains of bacteria and exacerbations of chronic obstructive pulmonary disease. $N$ Engl J Med 2002; 347: 465-471.

24 Sethi S, Sethi R, Eschberger K, et al. Airway bacterial concentrations and exacerbations of chronic obstructive pulmonary disease. Am J Respir Crit Care Med 2007; 176: 356-361.

25 Black P, Staykova T, Chacko E, et al. Prophylactic antibiotic therapy for chronic bronchitis. Cochrane Database Syst Rev 2003; 1: CD004105.

26 Suzuki T, Yanai M, Yamaya M, et al. Erythromycin and common cold in COPD. Chest 2001; 120: 730-733.

27 Banerjee D, Khair OA, Honeybourne D. The effect of oral clarithromycin on health status and sputum bacteriology in stable COPD. Respir Med 2005; 99: 208-215.

28 Seemungal TAR, Wilkinson TMA, Hurst JR, et al. Long-term erythromycin therapy is associated with decreased chronic obstructive pulmonary disease exacerbations. Am J Respir Crit Care Med 2008; 178: 1139-1147.

29 White AJ, Gompertz S, Bayley DL, et al. Resolution of bronchial inflammation is related to bacterial eradication following treatment of exacerbations of chronic bronchitis. Thorax 2003; 58: 680-685.

30 Rosell A, Monso E, Soler N, et al. Microbiologic determinants of exacerbation in chronic obstructive pulmonary disease. Arch Intern Med 2005; 165: 891-897.

31 Miravitlles M, Marín A, Monsó E, et al. Efficacy of moxifloxacin in the treatment of bronchial colonisation in COPD. Eur Respir J 2009; 34: 1066-1071.

32 Sethi S, Jones PW, Theron MS, et al. Pulsed moxifloxacin for the prevention of exacerbations of chronic obstructive pulmonary disease: a randomized controlled trial. Respir Res 2010; 11: 10

33 Friedman M, Serby CW, Menjoge SS, et al. Pharmacoeocnomic evaluation of a combination of ipratropium plus albuterol compared with ipratropium alone and albuterol alone in COPD Chest 1999; 115: 635-641.

34 Rennard SI, Anderson W, ZuWallack R, et al. Use of long-acting inhaled beta2-adrenergic agonist, salmeterol xinofoate, in patients with chronic obstructive pulmonary disease. Am J Respir Crit Care Med 2001; 163: 1087-1092.

35 Mahler DA, Donohue JF, Barbee RA, et al. Efficacy of salmeterol xinofoate in the treatment of COPD. Chest 1999; 115: 957-965.

36 Aalbers R, Ayres J, Backer V, et al. Formoterol in patients with chronic obstructive pulmonary disease: a randomized, controlled, 3-months trial. Eur Respir J 2002; 19: 936-943.

37 Calverley PM, Boonsawat W, Cseke Z, et al. Maintenance therapy with budesonide and formoterol in chronic obstructive pulmonary disease. Eur Respir J 2003; 22: 912-919.

38 Szafranski W, Cukier A, Ramirez A, et al. Efficacy and safety of budesonide/formoterol in the management of chronic obstructive pulmonary disease. Eur Respir J 2003; 21: 74-81.

39 Puhan MA, Bachmann LM, Kleijnen J, et al. Inhaled drugs to reduce exacerbations in patients with chronic obstructive pulmonary disease: a network meta-analysis. BMC Med 2009; 7: 2.

40 Calverley PMA, Anderson JA, Celli B, et al. Salmeterol and fluticasone propionate and survival in chronic obstructive pulmonary disease. N Engl J Med 2007; 356: 775-789.

41 Calverley P, Pawels R, Vestbo J, et al. Combined salmeterol and fluticasone in the treatment of chronic obstructive pulmonary disease: a rendomised controlled trial. Lancet 2003; 361: 449-456.

42 Gross NJ. Tiotropium bromide. Hot Topics Respir Med 2007; 5 15-19.

43 Anzueto A, Miravitlles M. Efficacy of tiotropium in the prevention of exacerbations of COPD. Ther Adv Respir Dis 2009; 3: 103-111.

44 Niewoehner DE, Rice K, Cote C, et al. Prevention of exacerbations of chronic obstructive pulmonary disease with tiotropium, a oncedaily inhaled anticholinergics bronchodilator. Ann Internal Med 2005; 143: 317-326.

45 Dusser D, Bravo M-L, Iacono P. The effect of tiotropium on exacerbations and airflow in patients with COPD. Eur Respir J 2006; 27: 547-555.

46 Barr RG, Bourbeau J, Camargo CA, et al. Tiotropium for stable chronic obstructive pulmonary disease: a meta-analysis. Thorax 2006; 61: 854-862.

47 Tashkin DP, Celli B, Senn S, et al. A 4-year trial of tiotropium in chronic obstructive pulmonary disease. $N$ Engl J Med 2008; 359: 1543-1554.

48 Powrie DJ, Wilkinson TMA, Donaldson GC, et al. Effect of tiotropium on sputum and serum inflammatory markers and exacerbations of COPD. Eur Respir J 2007; 30: 472-478.

49 Washko GR, Fan VS, Ramsey SD, et al. The effect of lung volume reduction surgery on chronic obstructive pulmonary disease exacerbations. Am J Respir Crit Care Med 2008; 177: 164-169.

50 Jeffery PK. Structural and inflammatory changes in COPD: a comparison with asthma. Thorax 1998; 53: 129-136.

51 Pauwels RA, Löfdahl C-G, Laitinen LA, et al. Long-term treatment with inhaled budesonide in persons with mild chronic obstructive pulmonary disease who continue smoking. N Engl J Med 1999; 340: 1948-1953.

52 Alsaeedi A, Sin DD, McAlister FA. The effect of inhaled corticosteroids in chronic obstructive pulmonary disease: a systematic review of randomized placebo-controlled trials. Am J Med 2002; 113: 59-65.

53 Jones PW, Willits LR, Burge PS, et al. Disease severity and the effect of fluticasone propionate on chronic obstructive pulmonary disease exacerbations. Eur Respir J 2003; 21: 68-73.

54 Jenkins CR, Jones PW, Calverley PM, et al. Efficacy of salmeterol/ fluticasone propionate by GOLD stage of chronic obstructive pulmonary disease: analysis from the randomised, placebocontrolled TORCH study. Respir Res 2009; 10: 59. 
55 De Miguel Díez J, Calle Rubio M, Rodríguez Hermosa JL, et al. Guidelines for the treatment of COPD. Hot Topics Respir Med 2007; 5: 7-14.

56 Roland NJ, Bhalla RK, Earis J. The local side effects of inhaled corticosteroids. Chest 2004; 126: 213-219.

57 Singh S, Amin AV, Loke YK. Long-term use of inhaled corticosteroids and the risk of pneumonia in chronic obstructive pulmonary disease. A meta-analysis. Arch Intern Med 2009; 169: 219-229.

58 Ernst P, Gonzalez AV, Brassard P, et al. Inhaled corticosteroid use in chronic obstructive pulmonary disease and the risk of hospitalization for pneumonia. Am J Respir Crit Care Med 2007; 176: $162-166$.

59 Hubbard RB, Smith CJP, Smeeth L, et al. Inhaled corticosteroids and hip fracture. A population-based case-control study. Am J Respir Crit Care Med 2002; 166: 1563-1566.

60 Kardos P, Wencker M, Glaab T, et al. Impact of salmeterol/ fluticasone propionate versus salmeterol on exacerbations in severe chronic obstructive pulmonary disease. Am J Respir Crit Care Med 2007; 175: 144-149.

61 Bleecker ER, Emmett A, Crater G, et al. Lung function and symptom improvement with fluticasone propionate/salmeterol and ipratropium bromide/albuterol in COPD: response by betaagonist reversibility. Pulm Pharmacol Ther 2008; 21: 682-688.

62 Wedzicha JA, Calverley PMA, Seemungal TA, et al. The prevention of chronic obstructive pulmonary disease exacerbations by salmeterol/fluticasone propionate or tiotropium bromide. Am J Respir Crit Care Med 2008; 177: 19-26.

63 Ferguson GT, Anzueto A, Fei R, et al. Effect of fluticasone propionate/salmeterol $(250 / 50 \mathrm{mcg})$ or salmeterol $(50 \mathrm{mcg})$ on COPD exacerbations. Respir Med 2008; 102: 1099-1108.

64 Miravitlles M, Anzueto A. Insights into interventions in managing COPD patients: lessons from the TORCH and UPLIFT studies. Int J Chron Obstruc Pulmon Dis 2009; 4: 185-201.

65 Aaron SD, Vandemheen KL, Fergusson D, et al. Tiotropium in combination with placebo, salmeterol, or fluticasone-salmeterol for treatment of chronic obstructive pulmonary disease. Ann Intern Med 2007; 146: 545-555.

66 Welte T, Miravitlles M, Hernandez P, et al. Efficacy and tolerability of the addition of budesonide/formoterol to tiotropium in COPD patients. Am J Respir Crit Care Med 2009; 180: 741-750.

67 Poole PJ, Black PN. Oral mucolytic drugs for exacerbations of chronic obstructive pulmonary disease: a systematic review. BMJ 2001; 322: 1271-1274.
68 Decramer M, Rutten-van Mölken M, Dekhuijzen PNR, et al. Effects of $\mathrm{N}$-acetylcysteine on outcomes in chronic obstructive pulmonary disease (Bronchitis Randomised on NAC Cost-Utility Study, BRONCUS): a randomised placebo-controlled trial. Lancet 2005; 365: 1552-1560.

69 Zheng JP, Kang J, Huang SG, et al. Effect of carbocysteine on acute exacerbation of chronic obstructive pulmonary disease (PEACE study): a randomised placebo-controlled study. Lancet 2008; 371: 2013-2018.

70 Steurer-Stey C, Bachmann LM, Steurer J, et al. Oral purified bacterial extracts in chronic bronchitis and COPD. Chest 2004; 126 : 1645-1655.

71 Prieto A, Reyes E, Bernstein ED, et al. Defective natural killer and phagocytic activities in chronic obstructive pulmonary disease are restored by glycophosphopeptical (Inmunoferon). Am J Respir Crit Care Med 2001; 163: 1578-1583.

72 Alvarez-Mon M, Miravitlles M, Morera J, et al. Treatment with the immunomodulator AM3 (Inmunoferon) improves the healthrelated quality of life of patients with chronic obstructive pulmonary disease. Chest 2005; 127: 1212-1218.

73 Miravitlles M, Murio C, Morera J, et al. Efecto de AM3 en la calidad de vida de pacientes con enfermedad pulmonar obstructiva crónica en subgrupos de riesgo. [Effect of AM3 on healthrelated quality of life in patients with chronic obstructive pulmonary disease belonging to risk groups]. Med Clin (Barc) 2008; 130: 688-692.

74 Poole PJ, Chacko E, Wood-Baker RWB, et al. Influenza vaccine for patients with chronic obstructive pulmonary disease. Cochrane Database Syst Rev 2006; 1: CD002733.

75 Alfageme I, Vazquez R, Reyes N, et al. Clinical efficacy of antipneumococcal vaccination in patients with COPD. Thorax 2006; 61: 189-195.

76 Stockley RA, Chopra N, Rice L. Addition of salmeterol to existing treatment in patients with COPD: a 12 month study. Thorax 2006; 61: 122-128.

77 Garcia-Aymerich J, Lange P, Benet M, et al. Regular physical activity reduces hospital admission and mortality in chronic obstructive pulmonary disease: a population based cohort study. Thorax 2006; 61: 772-778.

78 Bourbeau J, Julien M, Maltais F, et al. Reduction of hospital utilization in patients with chronic obstructive pulmonary disease. A disease-specific self-management intervention. Arch Intern Med 2003; 163: 585-591.

79 Wedzicha JA, Seemungal TAR. COPD exacerbations: defining their cause and prevention. Lancet 2007; 370: 786-796. 